\title{
T23 Frigate Power Generation and Machinery Controls Update (PGMU) - Let the trials commence
}

\author{
T. D. Peacock IMarEst IEng \\ Naval Design Partnering, UK MoD, Bristol, UK; Seconded from Babcock International Group \\ AuthorEmail: tim.peacock@babcockinternational.com
}

\section{Synopsis}

The Type 23 Frigate (T23) has been extended in-service well beyond its initial design life of 18 years, with some ships due to be over 35 years old when they leave service. To ensure the vessels remain capable and provide the required availability demanded by the Royal Navy a T23 Life Extension (LIFEX) programme was set up to meet this revised end of life. A significant element of this LIFEX and the focus of this paper is PGMU (Power Generation and MCAS Update).

This paper builds on other papers presented by my colleagues at previous conferences. This edition will cover issues that have arisen during the fit, lessons learnt that can be carried forward into future vessels and the test procedures of systems and equipment new to the Royal Navy.

Challenges during fit have arisen from;

- $\quad$ Limited space and access for the new equipment and systems

- The inability to survey some spaces before the work commenced to confirm dimensions against original drawings

- The provision of sufficient shock clearance during fit

- The requirement to use modern off the shelf commercial equipment and yet also to conform to Defence Standards, which in some cases are out of date and written to old fashioned Admiralty Specifications

- The physical integration of modern equipment and the re-designing of a legacy platform to new standards.

PGMU comes at a very interesting time for the Royal Navy, with a similar project following closely behind; the Power Improvement Plan (PIP) for Type 45 Destroyer (T45). In addition to PGMU and PIP, very similar DG sets are also being fitted to the T26 Frigates. The occurrence of three RN platforms using modern DG sets from the same family marks a turning point for the Royal Navy, where it has moved firmly into the 21 st century with regards to diesel electric power generation, and the changes in operating and maintenance procedures that this brings with it. Therefore, I will also touch on the challenges of Integrated Logistic Support at this stage of a project.

\section{Introduction}

The original designers of the T23 platform accurately predicted the electrical growth, and as the vessels approached the end of their expected life, the limit of the electrical margin was met. Therefore, the aim of PGMU is to reinstate a margin of electrical power generation while also overcoming equipment obsolescence. This is the largest Alteration \& Addition (A\&A) the T23 has ever seen and encompasses a significant sea water system upgrade which is a pre-requisite for the fit.

Another factor which necessitated the need for PGMU was that the vessels were originally designed in the early 1980s as Anti-Submarine Warfare (ASW) platforms, operating in the cold climate of the North Atlantic and the Greenland, Iceland, United Kingdom (GIUK) Gap. They now find themselves operating as general-purpose frigates in much warmer waters where due to insufficient cooling capacity their Diesel Generators (DG) are forced to operate at a decreased rating, typically $25 \%$ lower than design.

Simply put, PGMU replaces the electrical power generation system. Diesel generators with higher power output are being fitted in place of the original Paxman units, and similarly higher power motor generator sets are also being installed. This increase in electrical power generation has necessitated changes and upgrades to the switchboards, Machinery Controls and Surveillance System (MCAS) and as already mentioned, the sea water cooling system. 


\subsection{The story so far...}

Conceived back in 2007, it has taken considerable time and effort to get the PGMU project to the stage it is today. Following the usual Ministry of Defence appraisal and scrutiny procedures, the project was given the final go ahead in November 2013 and swiftly moved on to the procurement phase.

The equipment procurement and the production of a highly detailed installation solution took place simultaneously, and work began on installing the equipment on HMS Richmond in early 2017.

The project has opted for Commercial Off-The-Shelf (COTS) equipment to ensure lower procurement cost, the ease of supportability through life and to take advantage of the data gathered over millions of running hours throughout industry. In addition to this data, the PGMU equipment has undergone testing in order to validate the systems to classification societies, the International Maritime Organisation (IMO) \& military standards. This has resulted in very few modifications to the equipment and essentially what we are fitting to the T23 platform is the same as you will find throughout the world in merchant ships, offshore platforms and land based power generation facilities.

\subsection{Progress}

The upkeep period for HMS Richmond, the First of Class (FoC) for the PGMU fit commenced in September 2017. By the time of the conference, it is expected that equipment Setting to Work (STW) will have been completed and we will be preparing for extensive harbour and sea trials. At the time of writing, progress includes:

- The fitting of all major components within the scope of PGMU.

- New sea water system to provide cooling to the UAMR

- Installation of new uptakes and downtakes, including replacement exhaust silencers and IR reduction measures

- New cable runs for all control and instrumentation circuitry.

- All new Ethernet cabling replacing LAN and serial links

- New, updated processer cards for the entire Machinery Control and Surveillance (MCAS) system

- Updated mimic panels and new user interfaces in the Ships Control Centre to reflect the PGMU/ Related system fit

- Upgraded switchboards including additional laminate in the bus bars and updated instrumentation

- New Electrical Distribution Centres

- Onboard and shoreside spares, operator training, relevant documentation and spares codification have been introduced.

\section{Ship Systems}

\subsection{Sea Water System Changes}

The Upper Auxiliary Machinery Room (UAMR) power generation equipment introduces the requirement for an increase of approximately $30 \%$ in machinery cooling capacity. The current system utilises the ships HPSW system, reducing the pressure through orifice plates to levels appropriate for the power generation machinery. This setup brings with it several disadvantages, including excessive noise, erosion of the orifice plates leading over time to incorrect flow, and the need to run high volume pumps when demand is low. The changes now implemented into the SW supply to the UAMR provide separation of the existing HPSW system and the UAMR LPSW system. Two new LPSW pumps have been fitted within the Motor and Gear Room (MGR) on a central position (one pump mounted on top of the other within a frame) and one new LPSW pump is fitted in the Gas Turbine Room (GTR).

The removal of the UAMR cooling load from the HPSW system has allowed the removal of one of the 5 HPSW pumps whilst still increasing the water available for firefighting and similar purposes. As a further step, the HPSW pumps will now be shut down in normal conditions with the small parasitic load being supported by one of 2 new HPSW pressurising pumps. This new setup allows the HPSW system to revert to being primarily a fire main, reduces running hours on equipment and minimises the electrical load of the overall system. 
However, despite the positives of the modifications we have encountered setbacks during the fitting. During the design phase shock clearances for the equipment were taken into account, however not enough allowance was made between the pump volute casings and the pump support frames to allow for thrust and shock movement, and the thickness of the pump support framework meant that in certain circumstances a clash would occur; in some cases this was partially due to the pump mounting brackets being fitted in different positions to that expected. Given the overall state of the refit, resolution involved scalloping of the mounting frame box sections, leading to questions regarding the over-sizing of these in the first place and giving flexibility to reassess these on future fits.

\subsection{Composite Flanges}

To comply with the relevant Defence Standard composite flanges (sometimes referred to as slip on flanges) were not permitted on the T23 platform due to a perception that they could not withstand the required shock levels. However, the increased manufacturing tolerances that composite flanges allow as well as a much lower purchase price meant that the cost of further investigation was justified. It was highlighted that a typical fixed flange would cost three times more than a composite alternative and given the large quantity being fitted (approximately 1250) the savings possible were substantial.

\subsubsection{Shock testing of the composite flanges}

Before taking advantage of the cost savings related to the use of composite flanges, it was incumbent on our team to prove to the suitability of this design, specifically under shock conditions. A test rig was designed and built to include pipes of the various diameters found on the T23 SW system, each with a composite flange. There was also a length of pipe with the standard bolted flange which acted as a comparator.

The pipes were mounted using conventional manacle clamps on one or two supports depending on the size and weight of pipe. The pipes were filled with water and pressurised to 8 bar.

\section{Composite Flange Shock Test Bed}

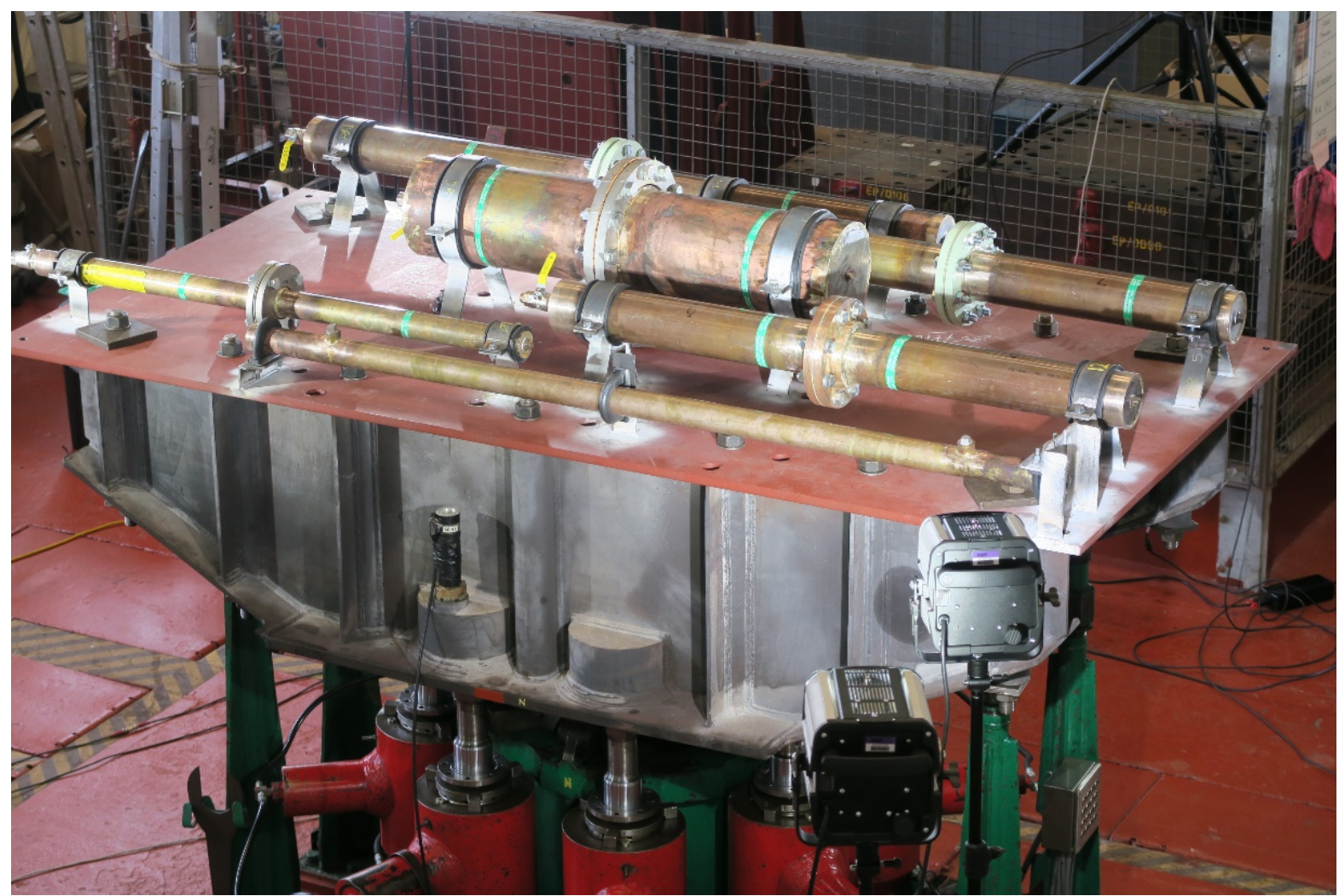

The rig was then subjected to various tests designed to replicate the different levels of shock seen throughout the vessel. As can be seen by the photographs although there was the expected flex of the flange fasteners which allowed a momentary release of water, the flanges survived without damage or degradation. However, an 
unexpected result of the test was the way in which the manacle supports failed by deformation of the fasteners on smaller bore pipes, and complete failure of the fasteners on the larger pipes.

\section{Deformation of the Pipe Clamp and Fasteners}

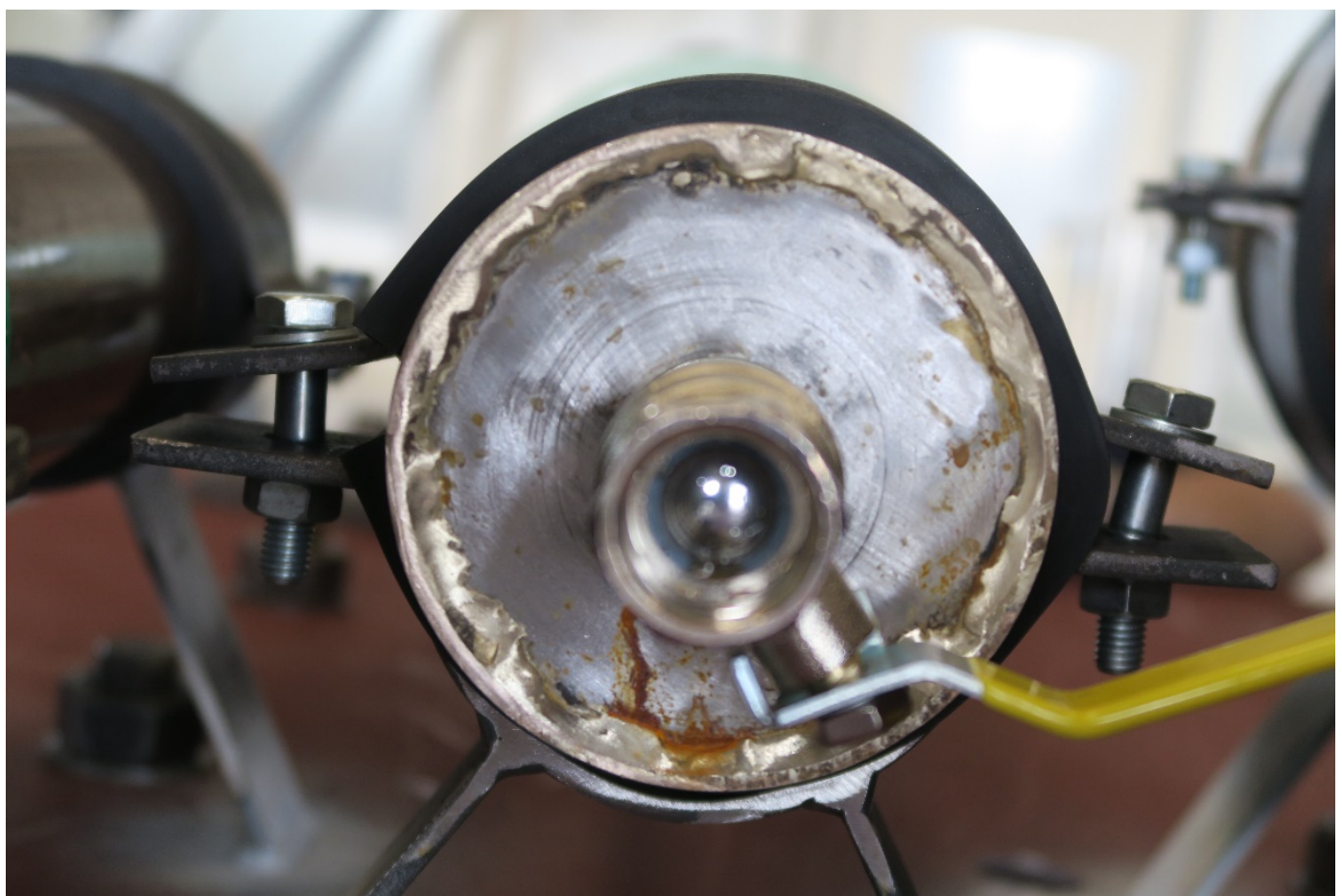

Failure of the Fasteners

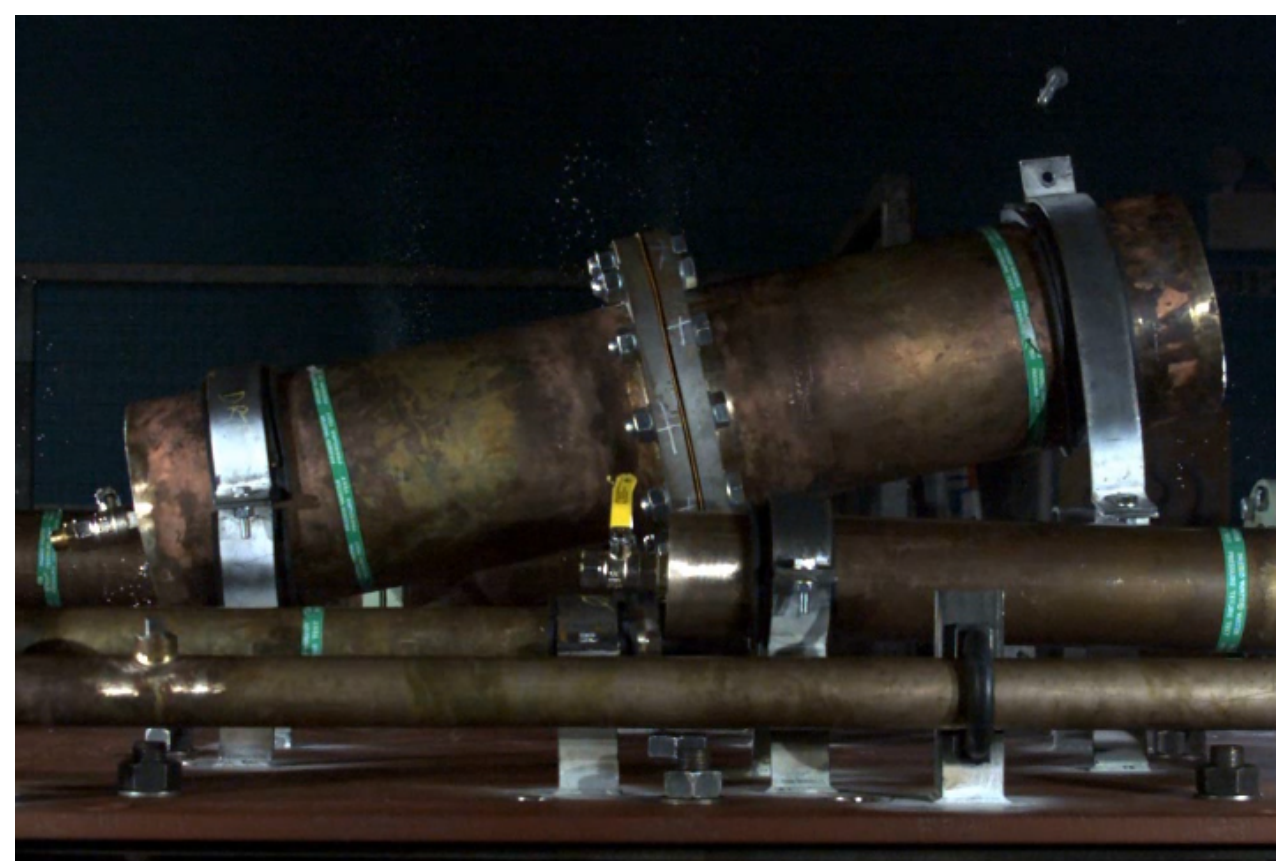

The issue was easily resolved by increasing the size of fasteners on the pipe clamps used on larger pipes, as proved by further shock tests the following day. Lessons learnt here have been applied to the fluid systems being fitted during the PGMU work. However, with these test results in mind, a look round any T23 platform shows 
numerous examples of clamps which would fail under a similar severity of shock event as those seen on the test bed.

\subsection{CO2 Fixed Fire Fighting System}

The ban on Halon fire extinguishers was implemented following the Montreal Protocol of 1987, albeit with an exemption to military applications. However, quite rightly the aspiration of the MoD Naval Authority Group (NAG) is to phase out the use of ozone depleting gases (ODG) and therefore replacement of the PGMU DG enclosure fire system could not employ the use of an ODG based suppressant. Several firefighting mediums were considered:

- Inergen (IG541) has the advantage of being breathable by humans at design concentration, and so appeared to be the natural replacement for Halon 1301. However, IG541 is stored as a gas and so the bottle size was considered too large and too heavy to be easily incorporated.

- Argonite (IG55) also cannot be liquefied at room temperature and so is stored as a gas leading to similar issues as IG541.

- Novec 1230 was also considered as it can be stored as liquid at room temperature, but this gas leaves toxic substances (hydro-fluoric acid) once exposed to high temperatures and so was discounted.

- An aerosol firefighting system was identified as offering a very compact, self-contained system. It is non-corrosive and does not produce toxic or corrosive by-products when exposed fire. This allows for re-entry and reinstatement of compartments without the aid of Self-Contained Breathing Apparatus provided the space has been ventilated to remove the products of combustion. However, this system was not approved by NAG for use in a frigate (or above) main machinery space and regrettably had to be discounted.

- Water mist system - Although attractive, the space envelope required for the full system was deemed too large.

- $\quad \mathrm{CO} 2$ can be stored as a liquid at room temperature and does not produce toxic substances once exposed to heat or fire. It was these qualities as well as the ease of availability worldwide which led to the decision to use $\mathrm{CO} 2$ as the firefighting medium in the FAMR module. This decision took into account the fact that $\mathrm{CO} 2$ poses a threat to life from asphyxiation and also that the gas has a life threatening toxicological impact on the human body at concentrations of $7 \%$ or higher.

\subsubsection{Mitigations to using a $\mathrm{CO}_{2}$ System}

With the hazards of $\mathrm{CO}_{2}$ listed above in mind, safe integration of $\mathrm{CO}_{2}$ within the compartment proved technically challenging. Various locations for the $\mathrm{CO}_{2}$ bottles outside of inhabited spaces were investigated (design standards state it should be stored in an upper deck compartment), however no practical alternative was available on board this particular platform.

To mitigate the inherent hazards of storing $\mathrm{CO}_{2}$ in a manned compartment a number of design changes have been incorporated, including:

- Increased localised ventilation around and particularly below the bottles has been added

- A leak detection system on the bottles

- An additional $\mathrm{CO}_{2}$ 'sniffer' leak detection system fitted below the bottles and in the bilge area

- Physical protection against accidental operation around the bottle discharge valves

- An interlock system, locking the system shut whilst the DG module doors are open

\section{$\bullet$}

\subsubsection{Testing of the system}

As this was effectively a new system to the T23 platform, a full functional test was required to validate the calculated $\mathrm{CO}_{2}$ concentration within the module after release. The system has two shots, each delivering a total of approximately $30 \mathrm{~kg}$ of $\mathrm{CO}_{2}$ from three bottles. In March 2018 such a test was undertaken at the MTU facility in Friedrichshafen and the following parameters were measured:

- The concentration of $\mathrm{CO}_{2}$ within the module over a 30 minute period

- Measurement of pressure within the enclosure 
- Temperature of the bottles before and after discharge

- Bottle weight before and after discharge

\section{$\mathrm{CO}_{2}$ Sensor Positions (3 in number) Within The Module}

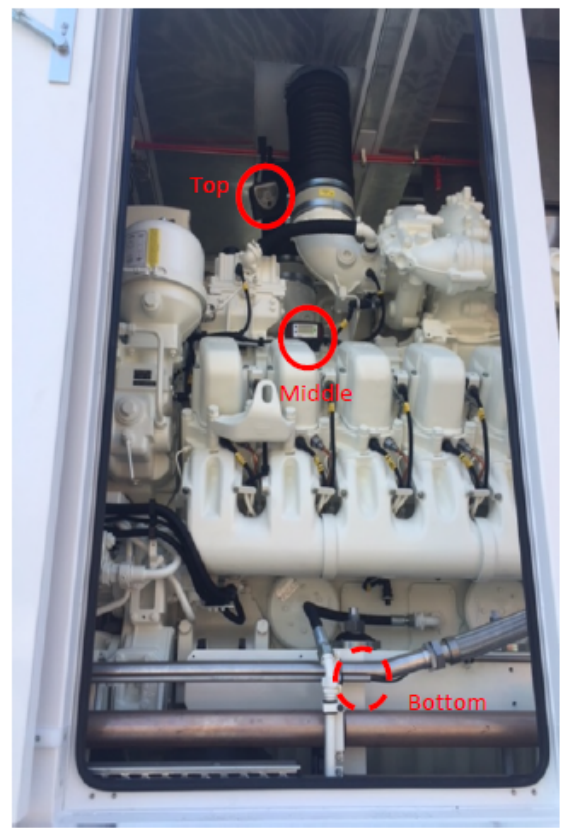

Draeger CO2 Measurement Gauge Positions

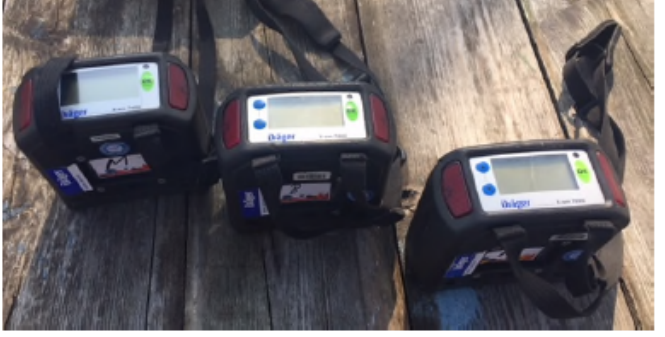

Draeger X-am 7000 CO2 Measurement Gauges

The temperature and weight of the bottles before and after the tests was also measured. For continuous pressure/temperature monitoring the temperature was measured using self-adhesive thermocouples mounted on the discharge valve of each bottle, the operating valve position by measuring the voltage across the solenoids and the module pressure via a $200 \mathrm{mB}$ pressure transducer.

\section{External Sensor Positions}
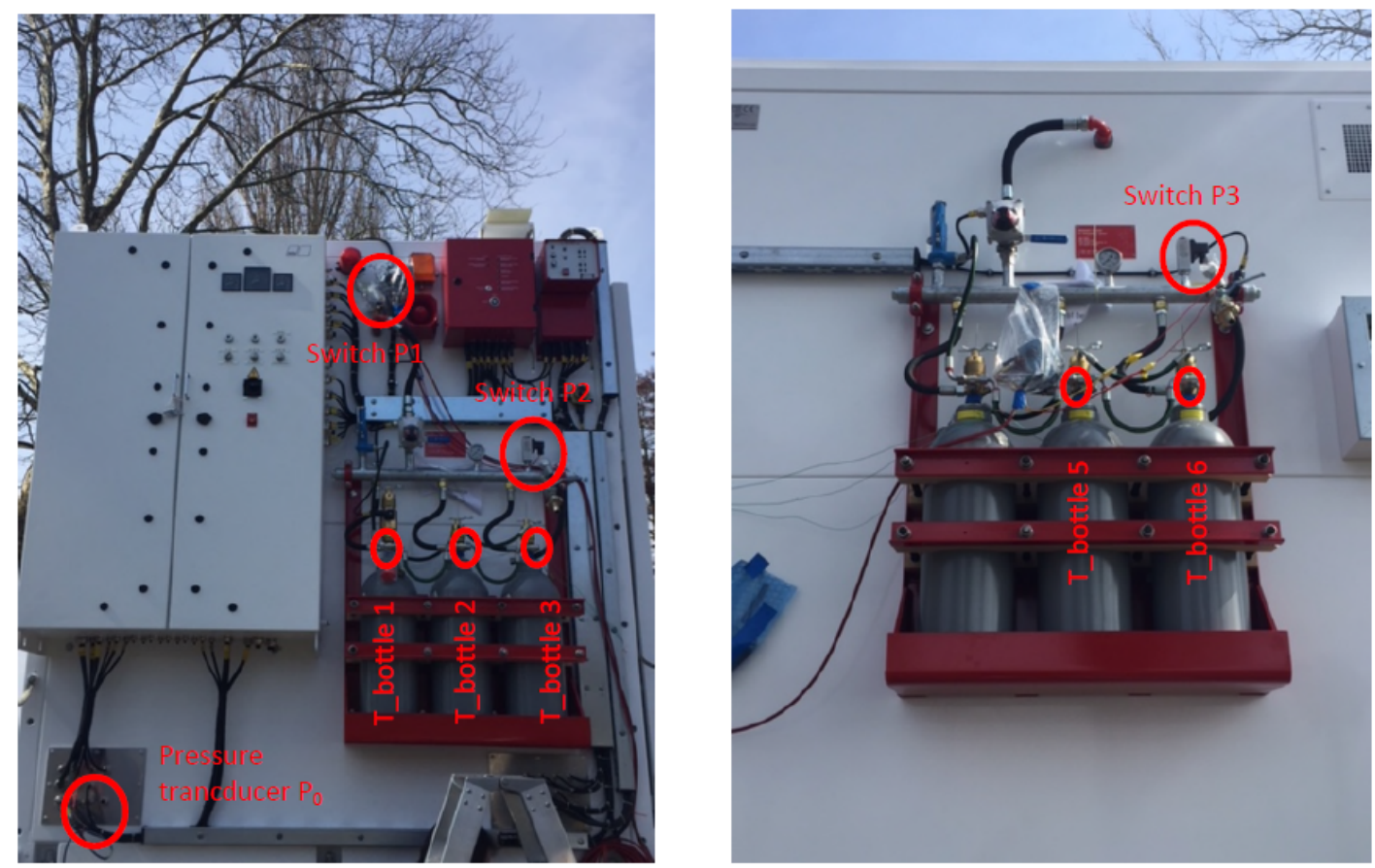

From our calculations before the test it was clear that we had over specified the amount of $\mathrm{CO}_{2}$ required to maintain the threshold of at least $33 \%$ over thirty minutes. However, we were unsure how gas tight the module 
would be so to determine this once the module had been vented after the first shot, the second shot only used two of the three $\mathrm{CO}_{2}$ bottles. The aspiration was to reduce the amount of $\mathrm{CO}_{2}$ held within the compartment thus reducing risk to personnel in the event of an accidental discharge into the FMAR, especially involving all twelve bottles.

Test 1 - Initial shot. After releasing the initial shot (three bottles, approximately $30 \mathrm{~kg}$ ) a maximum $\mathrm{CO}_{2}$ concentration of $58 \%$ was reached very quickly. This figure is the average across the height of the module. Over the thirty minute test period there was a decrease in concentration of just $6 \%$ giving a final reading of $52 \%$.

Test 2 - Secondary shot. The secondary shot was approximately $20 \mathrm{~kg}$ from two bottles. A maximum concentration of $43 \%$ was reached within the module. Over the 30 minute test period there was a decrease in concentration of approximately $4 \%$ giving a final concentration of $39 \%$.

\section{Test Results}

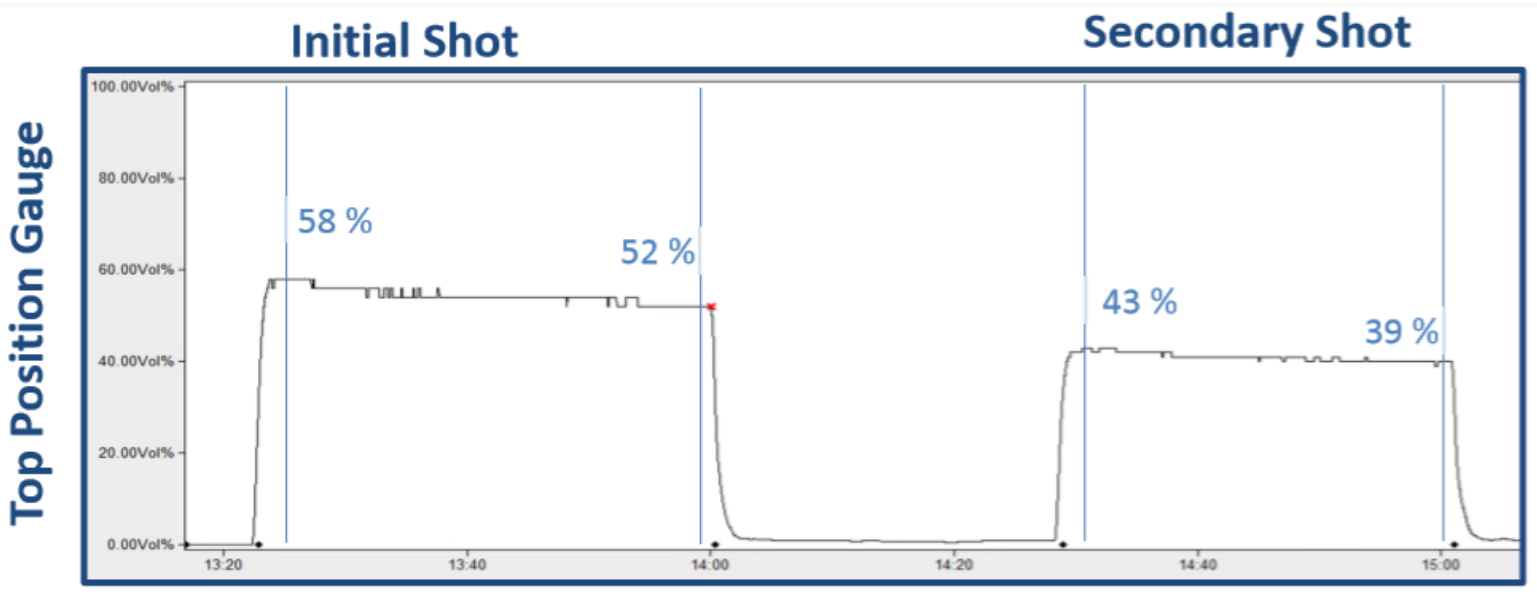

\subsubsection{Conclusions from the $\mathrm{CO} 2$ test}

Despite the success of the test and the verification that two $10 \mathrm{~kg} \mathrm{CO}_{2}$ bottles per shot are sufficient to reach and maintain the required saturation to extinguish a fire, the decision was taken to keep three bottles for each shot. This was to allow for degradation of the module seals over time, especially as panels are required to be moved during most maintenance routines on this particular DG set. That said, the bottles will be filled with slightly less $\mathrm{CO}_{2}$ which is effectively the 'tropical fill' level, thus removing the need to change the bottles when the vessel is operating in high ambient temperatures.

\subsection{Uptakes and Downtakes - Lessons Learnt}

The decision to renew the diesel silencers was based on several factors;

- Inspection of the internal parts of the existing silencers would have proved extremely difficult due to the nature of the perforated material within.

- There was also a requirement to improve upon the infrared signature of the exhaust plume, meaning that a significant part of the upper exhaust was going to be redesigned anyway.

- Significant calculations would have been required to ensure that the original silences would have provided the correct back pressure required for than new diesel engines.

- Finally, the original exhaust system did not meet the shock requirement and the project team was keen to rectify this.

Therefore, it was decided early in the project that to reduce risk, the intakes and up-takes (including silencers) should be replaced. Appropriate silencers which comfortably fitted in the space available were decided upon, however, it became apparent through the design process that although meeting the specification, these silencers would not be able to perform as well as desired in certain situations, namely alongside in port. There had been issues with other ships with "nuisance noise" affecting local communities when running DGs in port and it was 
considered that with port requirements getting tighter, there might be future limitations on port visits and so, at a late stage of the design it was agreed to change the silencers for a more effective design.

As mentioned previously, inability to access the foremast area meant that we were unaware of the material state of this section of the ship. Extensive corrosion of the structure coupled with significant degrading of the electrical cabling was discovered during the removal process. Both these issues caused delays and allowances will be made in future ships for such issues.

\section{A Section of the Degraded Cabling in the Mast}

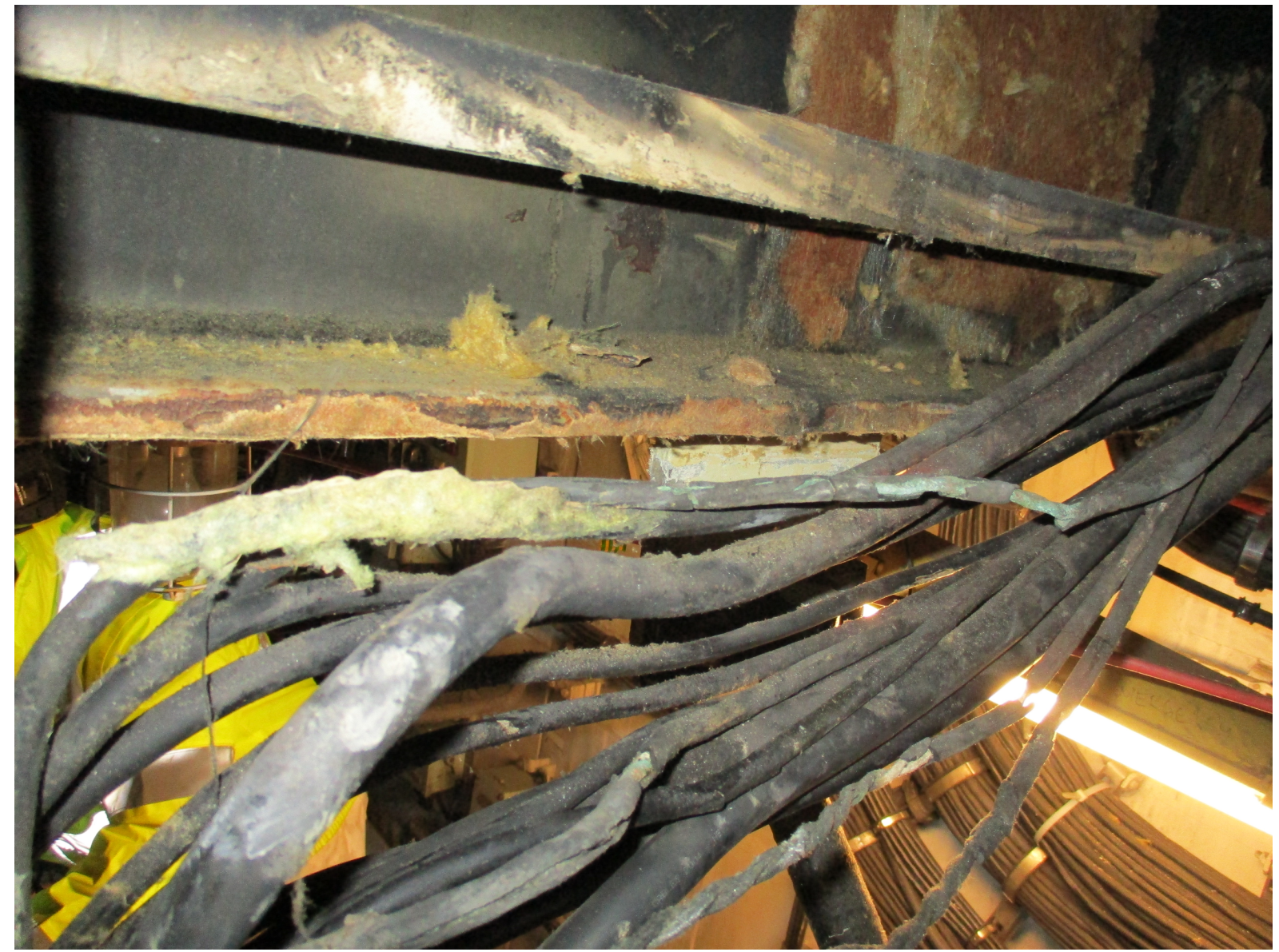

Due to the increased diameter of the new silencers, space was at a premium and in particular getting the up-takes to fit whilst allowing sufficient access around them was very difficult. We had specified that both the intake and exhaust trunking should come fitted with their supports. However, it soon became clear that due to minor differences between the 3D model of the relevant compartments and the spaces in the actual ship, significant work was required to modify the mounting points of the trunking on the ship. Changes have now been made to the specification of the uptake and down-take trunking and silencers which mean that the supports will be welded into place on board.

\subsection{Generator Main Power Cables}

Early in the design phase it was recognised that the main power cables to the generator would require a significant space envelope to allow for both sufficient bend radius and movement during a shock event. Consequently additional height was provided in the FAMR DG modules, however during installation, difficulties were still encountered, these lay in two areas; firstly that due to the thickness of the cables significant effort is required to bend them and this is further exacerbated when cable bends are in close proximity to each other; secondly, the gland plates on the generator and at the top of the module do not have the inherent strength to fully support the weight of the cables. As a consequence the cables run in a slightly different curve to that planned and a frame had to be designed and built to provide additional physical support and allow a smooth 
transition upwards to the gland plate in the top of the DG module without limiting movement under shock conditions.

Elsewhere in the main cable runs the design of the cable trays were specified to withstand the shock levels required of the platform. Now installed, it is clear that the calculations regarding stiffness of these trays took the weight of the cables into account but did not consider the benefit of the inherent rigidity of the cables themselves; as a result the trays are subjectively considered to be over engineered, adding weight, cost and taking up more space than necessary (this is being reviewed to see if savings can be made on follow on vessels).

\section{Different Ways Of Running And Maintaining}

It is fair to say that from an engineering perspective the Integrated Logistic Support part of any project does not hold the same interest as perhaps other aspects do. However, in this project with such a stark difference between the 1960 s technology being replaced and the 21 st century power generation being fitted it was essential to ensure that the correct spares training and maintenance packages were put in place to reflect the changes in modern upkeep practices.

A good example of this would be the maintenance routine on the cylinder heads of the MTU diesel engine. These cylinder heads remain untouched for the life of the engine while on the original Paxman diesels, the heads pistons and liners were all replaced midlife. Clearly this reduced maintenance offered savings in both spares holdings ashore and on board as well as a reduction in requisite tools. However, these savings also had to be balanced against the fact that a warship must always be capable of maintaining full operability.

To do this a clear policy of maintenance and support needed to be established right at the beginning of the project and consequently the whole PGMU ethos is built around full platform capability being available with just three out of the four diesel generators available, leaving one which can be taken down for maintenance or out of action due to failure at any time. It is also worth noting that whilst the switchboards busbars have been modified to carry the higher currents associated with the new equipment, the switchboards themselves are legacy equipment and therefore could fail under a full short circuit event when running 4 DGs in parallel.

Consequently, a relay has been fitted that will split the distribution in two if all 4 DGs are connected in parallel for longer than is required to changeover diesels. Therefore the "normal" operating philosophy onboard will be to operate with a maximum of 3 DGs on load with the $4^{\text {th }}$ shut down in standby as a "spare".

A formal "Logistical Demonstration" was written into all the equipment supply contracts. This consisted of several days in the relevant factories where by using the actual PGMU equipment, the OEM demonstrated the validity of their maintenance documentation by carrying out numerous maintenance routines witnessed by representatives from the project. These routines were mainly ones which operator/maintainers will be carrying out on a regular basis, and although clearly an additional cost, the process was proven to represent good value for money as a number of errors were found in the maintenance manuals. Another advantage of this process was to highlight the requirement - or not - for various OEM supplied tools. It quickly became clear that certain routines were impossible without the correct tooling, while others were entirely possible using standard tools held on board and did not require additional tools to be purchased.

Another a step change to maintenance on board the Type 23 platform, is the introduction of laptops to be used as diagnostic tools. This brings with it a host of security concerns where MTU agents, ship staff, or shore-side maintenance teams can access the control units of the diesel generators. To mitigate these risks significant effort was put into software security and ensuring that access to the relevant dongles and passwords are only available to those who have completed the associated training and have a genuine need to modify safety settings and equipment running parameters.

This issue will be encountered increasingly throughout the Royal Navy as modern equipment is introduced. Therefore, it needs to be considered early in any project as the route to gain the relevant accreditation and hence authorisation to use the equipment onboard is slow and convoluted, especially to those of us in the Marine Engineering branch who have not had the experience of say our WE colleagues.

Running legacy equipment alongside each other has meant that the support contracts required a different approach. Multiple contracts each supporting the different diesels and generators would have been confusing for the end user so a competition is currently being run for one contract covering all main DG sets on T23 platforms, 
with the expectation being that support for one of the brands of DG will be sub-contracted by a prime contractor.

\section{Summary}

It is at this point in the project where significant lessons can and are being learnt. Only when designs are actually put into place do assumptions, calculations, material specifications and design validation get truly tested. We will have the $2^{\text {nd }}$ ship starting her Refit before HMS Richmond undertakes sea trials and hence need to ensure lessons are passed on and common problems avoided and as such, are endeavouring to get as much knowledge transfer as possible by updating the design documentation, recording issues and solutions encouraging the upkeep contractor to move members of the production team across to the new vessel thus taking their experience to the new vessel, first hand.

A significant amount of money was spent on an extremely detailed installation document, and although it is impossible to prove whether this represented value for money, when the size of the work package is considered overall the modifications during fit have been minor and this suggests that the cost of the up-front design work did bring savings.

What has been very apparent during the project is that certain behaviours and actions which may appear arduous or costly, are essential to lower project cost growth;

- Vigorous testing of new components and equipment

- Continuous review of design

- Engagement with the stake holders throughout both design and build phases

- The strength to resist anything but essential change once the requirement and associated solution has been decided upon

What has also become clear is that without the decision on operation and maintenance being made very early on, the project would have found itself in a position where we had come through the pain of paying for an update and yet by continuing to use old maintenance, spares and tool holdings philosophy would receive none of the benefits and cost savings this update could bring to through life cost.

PGMU is still a fast paced, evolving project, and at the time of writing the next phase of the project; setting to work and testing of the whole package is about to begin. This work will be underway by the time EAAW VIII is presented, and we will have the power generation plant up and running with first of class testing imminent. Challenges relating to integration between the user interfaces, surveillance systems and equipment will doubtless be encountered. Therefore the presentation will expand on this paper, providing an update on any issues encountered during setting to work and potential challenges during the test phase. 